\title{
Kathryn Harley: 'often when we see paediatric patients it's already too late'
}

Please send any ideas for feature articles for consideration to:

Ruth Doherty,

Managing Editor,

British Dental Journal,

The Macmillan Building,

4-6 Crinan Street,

London,

N1 9XW

Email: r.doherty@nature.com

Kathryn Harley, Dean of the Faculty of Dental Surgery of the RCS, talks to the British Dental Journal about working with the press to spread oral health messages, the importance of prevention and the joy of treating children.

\section{What can we do to improve the general oral health of the population?}

As a profession we are fairly responsive to our patient needs but we still have a job to do in oral health education. In the UK, we really shouldn't have the levels of dental disease that we still have.

At the Faculty, we have been working hard with our RCS press team to try to get more oral health messages out to the general public. Using the press allows us to put across some simple messages to a large audience, for example: 'it is advisable for the parent/ guardian to brush children's teeth until they are approximately seven years old, or when they are able to write their own name legibly as this indicates that the child has sufficient manual dexterity to handle a toothbrush without assistance.

Another topic we are keen to raise awareness around is the level of acidity in drinks. Over the last 30 years, due to the increased consumption of acidic drinks in the patient population, tooth wear has escalated. We are keen that not only is sugar content referred to on food labels but also the $\mathrm{pH}<7$ (acidity). A large proportion of the general public are unaware of the danger of acidic beverages and the detrimental effect to teeth, which include juices marketed as healthy drinks.

I also think we have a role to educate other health professionals about oral

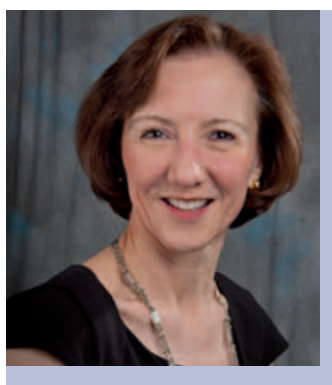

Kathryn Harley is a consultant in paediatric dentistry and is also the Dean of the Faculty of Dental Surgery of the Royal College of Surgeons (RCS) of England. Miss Harley was elected to this role in 2011 for a three-year term of office. Kathryn graduated from Guy's Hospital Dental School in 1981 and completed a Masters degree in Conservative Dentistry at the Eastman Dental Institute in 1986, where she was appointed Consultant and Honorary Senior Lecturer in Paediatric Dentistry in 1991. In 1999, she was appointed Consultant in Paediatric Dentistry at the Edinburgh Dental Institute where she was Head of Department, 1999-2011. In 2010, Miss Harley completed ten years as a member of the Board of Dental Protection Limited, having been chairman for the last four. She has been a FDS board member since 2002 and outspoken in the promotion of good oral health and nutrition for children.

health. For example health visitors often recommend fruit juice to patients for their nutritional benefits, but this can lead to dental disease unless consumed at meal times only.

A study carried out in Glasgow last year revealed that the general public are also unaware of the sugar content in drinks such as juices and smoothies. ${ }^{1}$ Furthermore, parents are giving their children dried fruit for healthy snacks, which causes further dental disease, unaware that these are very high in sugar. The Faculty faced a difficult challenge in trying to get this message across without seeming to be anti five-a-day, which of course would never be the case. We have been trying to stress that five glasses of fruit juice cannot really be recommended as your five-a-day and that a variety of fruit and vegetables should be given at mealtimes only. When I see patients, I always say to their parents: 'if your child is eating plenty of fruit and vegetables you don't need to give them juice; they should be drinking water and milk only.'

Do you feel that a 'fat tax' on unhealthy foods, for example fizzy drinks, would help to improve oral health in the UK?

I would be quite happy with raising the cost of unhealthy, carbonated drinks although I don't know if it would deter people. I think it is wrong that bottles of carbonated fruit drink are cheaper than mineral water. The cost must inevitably affect peoples' choices. If a parent, filling up their supermarket trolley, is worried about the weekly budget then carbonated, fruit drinks that are cheaper than bottled water are likely to appeal.

Our tap water in the UK is often a neglected resource. It is very safe to drink and its quality is excellent. When children are weaned off breast- or 
bottle-milk it is important that parents are encouraged to give them milk or water instead of juice. If young children are given squash or diluted juice it is often difficult for parents to introduce water to them as older children as they will have developed a taste for flavoured drinks.

\section{What is your view in the 'Direct Access' debate?}

The Faculty is seeking opinion from our fellows and members on this subject. There are those that have no problem with it and those that feel it should be restricted. Personally, I think that the right care should be delivered by the right people at the right time.

\section{Your own speciality is paediatric dentistry - what is the biggest challenge in this area for dentists?}

I really want to emphasise the fact that prevention is key and we have an enormous hurdle to get over to communicate this effectively to the general public. However, once the child has dental disease we need dentists to a) diagnose it and b) intervene. If the dentist can't intervene themselves they should refer it to a specialist or to somebody who will actually provide the appropriate treatment. The trouble with dentistry for children is that not every practitioner is comfortable managing a child. Many watch and see if their diet advice will stop the progression of disease as they don't feel confident carrying out what is required by way of operative treatment. Often when we see the child patient it's too late and we end up having to take out large numbers of teeth under general anaesthesia. Over the last three years, dental caries has consistently been one of the top five reasons for children to be admitted to hospital and the most common reason for a child to have a general anaesthetic. $^{2}$

In a busy practice, children often take time to treat and require a different approach. Some people are very comfortable managing children whereas others aren't. That's not a criticism of the dentist. It is no different to some people feeling comfortable placing implants and others not. Unfortunately, children who need treatment are not always treated and we end up having to deliver more radical treatment than would have been necessary if caries or erosion had been diagnosed and managed at an earlier stage.

I'm concerned that the number of paediatric specialists is diminishing when it should be increasing. There is still a need for more consultants and specialists as paediatric dentistry is relatively underrepresented considering the number of children that require specialist care.

\section{You say there is a shortage of paediatric dentists - why is this?}

It's a relatively young speciality comparably speaking. There are only 80 consultants in the UK in total, but as many are part-time this equates to approximately 62 full time dentists. It's a tiny number and there should be significantly more. There are insufficient numbers of trainees coming through which means that when paediatric dentists leave or retire we could potentially be facing a situation where there is no one to replace them. We need to address this otherwise in future there will be fewer specialists.

I believe that dentistry takes up about 5\% of the total NHS budget. If that is the case, considering much oral disease is preventable, efforts should be directed at reducing this cost. In the same way as there is a big Department of Health push to improve care and reduce the incidence of diabetes (diabetic care currently draws on approximately $10 \%$ of the total NHS budget), it would be fantastic if we could have a similar campaign to improve oral health.

\section{Globalisation is a feature of our lives today - how does dentistry fit into this new world view?}

The RCS has fellows and members throughout the world, traditionally training overseas postgraduates and taking our exams to other countries where we lecture by invitation. We, as a Faculty, have very strong links with our neighbours overseas and many leaders of international dental institutions received some of their training in the UK. One year ago when visiting Malaysia as an examiner for their postgraduates in paediatric dentistry, I realised that I had either worked with or helped train all of the senior staff who had postgraduate qualifications in the UK.
The same can be said of the UK where we send many of our trainees to other countries to help them develop their knowledge and skills base. We have many highly specialised dentists in the UK who have worked in other parts of the world.

\section{What do you feel is the general view of the general public towards dentists?}

The 2012 OFT report ${ }^{3}$ implied that the public's view was good. I think that the vast majority of dentists deliver excellent care for the majority of their patients. Good dentists tend to have very good communication skills. A lot of our time is spent actually talking to the patients so you can explain what you are about to do and why you are doing it - this is particularly important when treating children. Considering the time constraints and funding the level of dentistry delivered is generally well perceived by the public.

\section{What has been the proudest moment in your own career?}

I get huge satisfaction seeing my trainees finish specialist training and start new jobs. I'm so proud to have many of my trainees now eminent in my speciality in different areas of the country. What better way to see the fruits of your labour? That is the best thing for anybody to see that you are managing to a) treat and look after your patients in a way that is useful and beneficial for them, and b) know you are training other dentists to provide the same level and better care.

\section{What is the key to treating paediatric patients?}

Talking to patients is key. Successfully treating child patients is about having confidence in your own ability to do so. Paediatric dentistry is harder than people think because a child picks up on a dentist's confidence but if you are pretty convinced that you can deliver the treatment pain-free that confidence allows the child to relax more. Sometimes when you get a dentist who is not confident in treating children the child picks up on that anxiety and refuses to cooperate. We quite often get referral letters saying ' $X$ needs the following treatment and is 
uncooperative; I suspect they need a general anaesthetic' but in fact they are able to manage dental treatment delivered by a dentist who can take the time to acclimatise them and alleviate their fears. That's why I say we need the right people delivering the right care in the right place at the right time. The right place may well be a child-friendly surgery or an environment where the child doesn't feel uncomfortable.

\section{What advice would you give to dentists choosing a speciality?}

The Faculty provide careers advice in our careers booklet. ${ }^{4}$ I would advise people interested in a speciality to look at this and to contact the Faculty to find out more information.

I knew I wanted to be a paediatric dentist as an undergraduate as I love treating children. There is no better reward than having a child come in who is anxious and fearful, perhaps with discoloured teeth, and see them walk out smiling following treatment. Their mother might turn around to say that ' $X$ hasn't ever smiled like that before'. My own patient cohort predominantly consists of children with dental anomalies, such as children with amelogenesis imperfecta or hypodontia.
I had a lovely case where I had a little boy who was three years old with anodontia. His mother was keen that he should have some teeth and assured me that he wanted them. I told her I could make him some dentures but I wasn't convinced he would cooperate for the procedure. I worried that it was his mum who was more concerned about the lack of teeth than the child and wanted this rectified. She reassured me that he wanted the dentures. So following appointments for impressions and records, I made the child dentures at developmental milestones and he has worn them pretty much every day since! He's now eleven. You can see the difference in his demeanour in the pictures at presentation and once he received his teeth. I needed to see it to believe it myself but it really was making a colossal difference to this three-yearold. It was absolutely fantastic, he was really thrilled.

You are currently the 23rd Dean of the Faculty of Dental Surgery at the Royal College of Surgeons (RCS) - what are your main goals while in this position?

Our particular remit at the RCS is to support the fellows and members of the Faculty. We are a professional body committed to enabling dental surgeons to achieve and maintain excellence in practice and patient care.

With the need for financial savings in the NHS and competing priorities, a key aim of the Faculty is to ensure the numbers of specialists in hospitals, practice and the salaried dental services are not greatly reduced.

We need to make sure that we have enough appropriately trained people to deliver the right care in the right environment to patients who need it. To that end we are working with the Department of Health to establish care pathways currently in oral surgery and paediatric dentistry with a view to assisting the development of care pathways in other specialities.

Interview by Ruth Doherty, $B D J$ Managing Editor

1. University of Glasgow. UK public underestimating sugar levels in popular drinks. Press Release, April 2012. Available online: http://www.gla.ac uk/news/headline_230642_en.html (accessed January 2013).

2. The NHS Information Centre for health and social care. Hospital Episode Statistics. HESonline: http:// www.hesonline.nhs.uk.

3. Office of Fair Trading. Dentistry: an OFT market study. London: OFT, May 2012. Available online: http://www.oft.gov.uk/shared_oft/market-studies/ Dentistry/OFT1414.pdf (accessed January 2013).

4. RCS information on careers in dental surgery can be found at: http://www.rcseng.ac.uk/fds/careersin-dentistry (accessed January 2013) 